\title{
Molecular analysis of CIB4 gene and protein in Kermani sheep
}

\author{
M.R. Mohammadabadi, A.H.D. Jafari and F. Bordbar \\ Animal Science Department, Shahid Bahonar University of Kerman, Kerman, Iran
}

\begin{abstract}
The human calcium- and integrin-binding protein (CIB) family is composed of CIB1, CIB2, CIB3, and CIB4 proteins and the CIB4 gene affects fertility. Kermani sheep is one of the most important breeds of Iranian sheep breeds. The aim of this study was to analyze for the first time molecular characteristics of the CIB4 gene and protein in Kermani sheep. Different tissues were collected from the Kermani sheep and real time PCR was performed. The PCR products were sequenced, comparative analyses of the nucleotide sequences were performed, a phylogenetic tree was constructed, and different characteristics of CIB4 proteins were predicted. Real time PCR results showed that the CIB4 gene is expressed only in testis of Kermani sheep. The cDNA nucleotide sequence was identical with small tail Han sheep, cattle, goat, camel, horse, dog, mouse and human, respectively $100,99,99,98,98,96,96$, and $96 \%$. Hence, it can be suggested that the CIB4 gene plays a role in male fertility. Based on the phylogenetic analysis, sheep CIB4 gene has a close relationship with goat and cattle first, and then with camel and whale. Although we demonstrated that CIB4 is a testis-specific gene, expressed only in the testis and it interacts with other proteins, the mechanisms by which CIB4 expression is regulated need to be elucidated.
\end{abstract}

Key words: CIB4 gene; Kermani sheep; Molecular characteristics; Testis; Interaction

\section{Introduction}

The human calcium- and integrin-binding protein (CIB) family is composed of CIB1, CIB2, CIB3, and CIB4 proteins and their molecular weight is approximately $22 \mathrm{kDa}$. Their EF-hand domains are important in $\mathrm{Ca}^{2+}$ binding, therefore, CIB family plays important roles in different tissues (1-3). It has been shown that the CIB1-3 proteins are a-helix rich upon binding $\mathrm{Ca}^{2+}$ or $\mathrm{Mg}^{2+}$ and have stable tertiary structures when bound to $\mathrm{Ca}^{2+}$ or $\mathrm{Mg}^{2+}$, but for CIB4 this is not completely explicit. CIB proteins also have a hydrophobic patch that can interact with the fluorescent probe 8-anilino-1-naphthalene-sulfonate, which has been demonstrated in many additional typical calcium sensor proteins; however, this binding is not always directly related to calcium binding (4). It has been found that CIB1 acts as a specific binding adjunct for the cytoplasmic domain of the platelet integrin allb subunit (5). After detection of CIB1, 3 other isoforms CIB2, CIB3, and CIB4 were recognized (6). It has been proven that mammalian CIB1 functionally affects hemostasis, DNA damage response, apoptosis, embryogenesis (1), endomitosis (7), and spermatogenesis (8). Other names for this protein are KIP (9) and calmyrin (10). To date, human CIB2-4 are identified less frequently than $C I B 1$. However, expression and function of these 3 genes have been introduced in other mammalian species. It has newly been proven that the CIB2 gene is expressed in the brain of rat (11) and in skeletal muscle of mouse, where the produced protein can interact with the integrin $\alpha 7 \mathrm{~B}$ subunit (12). Furthermore, researchers demonstrated that a $C I B 1$ gene knockout mouse displays no overt defect in platelet function (2), which suggests that $C I B 2, C I B 3$, and $C I B 4$ members can compensate for CIB1 loss. Moreover, it has been shown that CIB1, CIB2, and CIB3 proteins bind the integrin allb subunit in mouse in vitro (2). It has been proven that the CIB2 gene is expressed in various sheep tissues, including liver, heart, kidney, brain, spleen, stomach, ovary, testis, and muscle (13). Moreover, expression level of $C I B 2$ in these tissues is relatively higher than $C I B 3$ and CIB4 (13). Differently, CIB3 and CIB4 expressed selectively in different sheep tissues. Expression levels of CIB3 in the heart, stomach, ovary, testis, and muscle are relatively low (13). It has been shown that the CIB4 gene expresses only in the testis (3).

There are more than 50 million heads of sheep in Iran, of 27 breeds and ecotypes (14). One of the most important breeds of Iranian sheep is Kermani sheep that is well

Correspondence: M.R. Mohammadabadi: <mmohammadabadi@yahoo.ca>

Received January 5, 2017 | Accepted July 7, 2017 
adapted to harsh environmental conditions of the SouthEastern part of country, where dry and hot weather is prevalent and pastures are of low quality and quantity. Therefore, increasing the number of animals is not feasible; it is better to improve growth and fertility traits and consider molecular mechanisms of genes affecting these traits. On the other hand, it has been shown that the CIB4 gene is expressed only in the testis (3), and mammalian CIB1 functionally affects hemostasis, DNA damage response, apoptosis, embryogenesis (1), endomitosis (7), and spermatogenesis (8), thus it may be associated with growth and fertility traits. Studying expression and molecular mechanisms of this gene can help to understand its role in fertility and improve growth and fertility traits in Kermani sheep. Although many researchers have studied Kermani sheep (15-19), up to now, expression studies were not implemented, especially on CIB4 gene. Hence, the aim of this study was to analyze the molecular characteristics of CIB4 gene and protein in Kermani sheep.

\section{Material and Methods}

Tissues including brain, heart, lung, spleen, kidney, liver, ovary, and testis ( 3 repeats from each tissue) were collected from Kermani sheep (4 males and 2 females) after slaughter. Tissue samples were immediately frozen in liquid nitrogen and stored at $-80^{\circ} \mathrm{C}$.

Total RNA was isolated from each tissue sample using a One Step RNA Reagent Kit (Biobasic Co. Ltd., Iran). The RNA concentration was assessed by spectrophotometry at $260 \mathrm{~nm}$, and RNA quality was assessed by the absorbance $260 \mathrm{~nm}: 280 \mathrm{~nm}$ ratio and electrophoresis on $2 \%$ agarose gel stained with ethidium bromide.

RNAs were reverse transcribed with RerertAid ${ }^{\mathrm{TM}}$ H Minus First Strand cDNA Synthesis Kit (\#K1631, Fermentase Co., Iran) and an oligo $\mathrm{d}(\mathrm{T})$ primer was used according to manufacturer's protocol. An input of $1 \mu \mathrm{g}$ total RNA was used for the reaction.

Primers 5'-CATGGGGCAATGTCTGAGGT-3' and 5'-GGTATTTGTGTTCACGTCAAC-3' for CIB4 gene and 5'-CTGCTGACGCTCCCATGTTTGT-3' and 5'-CTGCTG ACGCTCCCATGTTTGT-3' for GAPDH gene used for RT-PCR were synthesized by Bioneer Co. (Iran). GAPDH was used to normalize the gene expression data as an endogenous control in the quantitative analysis of RT$\mathrm{PCR}$, since in some experimental systems its expression is very constant.

Samples were amplified using power SYBR Green PCR Master Mix (Iran). All reactions were performed with optical 96-well skirted microplates. Reactions were carried out in a volume of $15 \mu \mathrm{L}$ consisting of $2 X$ SYBR Green PCR Master Mix, $7.5 \mu \mathrm{L}$; template cDNA, $1.5 \mu \mathrm{L} ; 10 \mu \mathrm{M}$ forward and reverse primers, $1 \mu \mathrm{L}$; ROX, $0.3 \mu \mathrm{L}$ and $\mathrm{ddH} 2 \mathrm{O}, 4.7 \mu \mathrm{L}$. PCR protocol was done at $94^{\circ} \mathrm{C}$ for $5 \mathrm{~min}$, then 40 cycles of $94^{\circ} \mathrm{C}$ for $30 \mathrm{~s}, 59^{\circ} \mathrm{C}$ for $60 \mathrm{~s}$, and $72^{\circ} \mathrm{C}$ for $45 \mathrm{~s}$ and final extension at $72^{\circ} \mathrm{C}$ for $1 \mathrm{~min}$. To exclude the contamination of unspecific PCR products such as primer dimers, melting curve analysis was generated to all final PCR products.

PCR efficiency $(E)$ was estimated for each primer pair, standard curve arbitrary units were set and dilutions of 1 , $0.1,0.01$, and 0.001 were made. Fold change in gene expression was calculated using Pfaffl method (20). PCR products of CIB4 gene from Kermani sheep were purified from gel using QIAquick Gel Extraction Kits (Qiagen, Iran) and sent to Bioneer Co. (South Korea) for sequencing. Comparative analyses of the nucleotide sequences were performed online at $\mathrm{NCBI}$ (http://www.ncbi.nlm.nih/gov) and the phylogenetic tree was constructed by MEGA4.1 (21). Predictions of open reading frames and theoretical molecular weights of deduced polypeptides were made by the protein property calculator (http://www.basic.northwestern.edu/biotools/proteincalc.html). The protein isoelectric point was predicted (http://isoelectric.ovh.org/). The domain of Kermani sheep CIB4 protein was predicted with SMART software (http://smart.embl.de/). Prediction of protein characteristics and three dimensional structures were provided by Molecular Bioinformatics Center of National Chiao Tung University (http://ps2v2.life.nctu.edu.tw). The STRING program was used for representing predicted protein interactions (http://string-db.org/version_10).

\section{Results}

The $260 \mathrm{~nm}: 280 \mathrm{~nm}$ ratio ranged from 1.77 to 1.90 , which showed that extracted total RNA was of good quality and not contaminated. Furthermore, all RNA extracted from brain, heart, lung, spleen, kidney, liver, ovary, and testis of the Kermani sheep used in the present study revealed two $18 \mathrm{~S}$ and $28 \mathrm{~S}$ bands (Figure 1).

To find the proper annealing temperature for primers of CIB4 gene and GAPDH control gene, gradient PCR was carried out and the optimal annealing temperature for the specific primers was determined at $59^{\circ} \mathrm{C}$. Results of real time PCR curves and products on $2 \%$ agarose gel showed that a fragment with $574 \mathrm{bp}$ for CIB4 gene was expressed only in testis tissue of Kermani sheep and was not detected in brain, heart, lung, spleen, kidney, liver and ovary tissues (Figure 2). A fragment with $150 \mathrm{bp}$ for GAPDH was observed in all tissues (Figure 3). Expression level using Pfaffl method for testis tissue was 0.74 and for other studied tissues the level was 0 .

The cDNA nucleotide sequence in Kermani sheep (GenBank accession No. KJ425421.1) was identical with small tail Han sheep, cattle, goat, camel, horse, dog, mouse and human, respectively $100,99,99,98,98,96,96$, and $96 \%$. The nucleotide sequences of CIB4 gene in Kermani sheep were aligned with other homologous species to elucidate the phylogenetic tree (Figure 4). 
The deduced CIB4 protein of Kermani sheep consisted of 185 amino acid residues, its predicted molecular weight was $21,650 \mathrm{~g} / \mathrm{mol}$ for the unmodified protein and the estimated isoelectric point was 4.46. Extinction coefficient and approximate volume were $19,780 \mathrm{~cm} / \mathrm{m}$ and $26,197 \mathrm{~A}^{3}$, respectively. The basic amino composition is reported in Table 1. Comparison of these amino acids demonstrated that the total number of negatively charged residues (Asp + Glu) and the total number of positively charged residues (Arg + Lys) are 31 and 15, respectively.

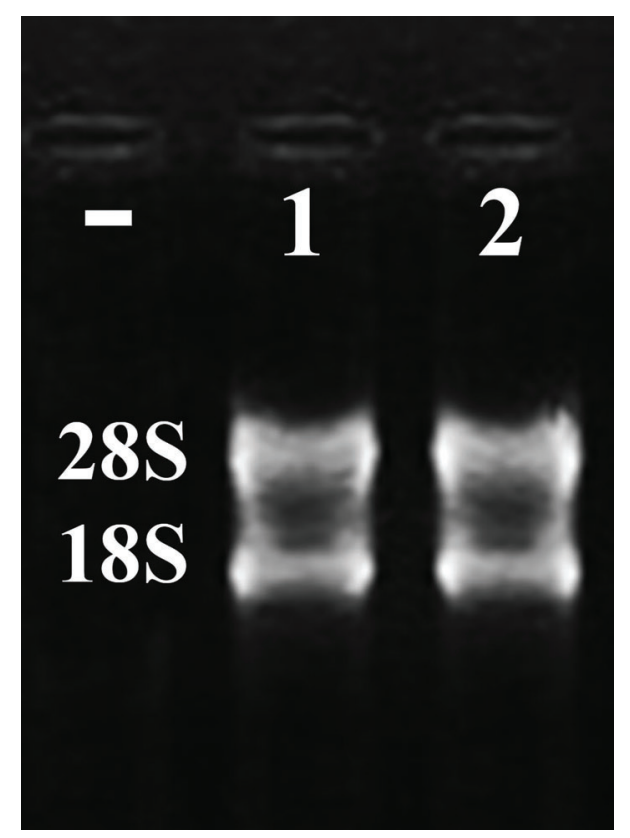

Figure 1. Samples of the extracted total RNA from the Kermani sheep.
Predicted domains of Kermani sheep CIB4 protein with SMART software showed that the deduced sheep CIB4 protein contains two characteristic EF-hand domains, which is similar to the CIB4 in other species. The first EF-hand domain starts at amino acid position 101 and ends at amino acid position 129. The second EF-hand domain starts at amino acid position 143 and ends at amino acid position 171. In these 2 domains, CIB4 protein has $8 \mathrm{Ca}^{2+}$ binding sites. CIB4 protein also has a region named FRQ1 that starts at amino acid position 21 and ends at amino acid position 173 (Figure 5). The predicted secondary structure of the CIB4 in Kermani sheep showed $59.46 \%$ helix $(\mathrm{H})$ and the remainder $40.54 \%(\mathrm{C})$. EF-hand domains have calcium binding motif that contains diverse superfamily of calcium sensors and calcium signal. Protein characteristics and three-dimensional structures of CIB4 for Kermani sheep are shown in Figure 6. Kermani sheep CIB4 protein interaction with other predicted proteins and description of predicted functional partners using

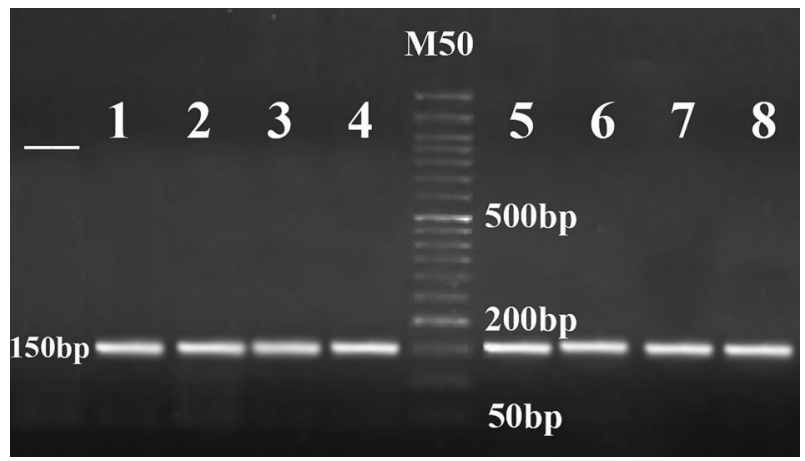

Figure 3. Electrophoresis of studied samples using GAPDH primers in Kermani sheep on agarose gel. M50: size marker. Lanes 1-8 are brain, heart, lung, spleen, kidney, liver, ovary and testis, respectively. -: negative control.

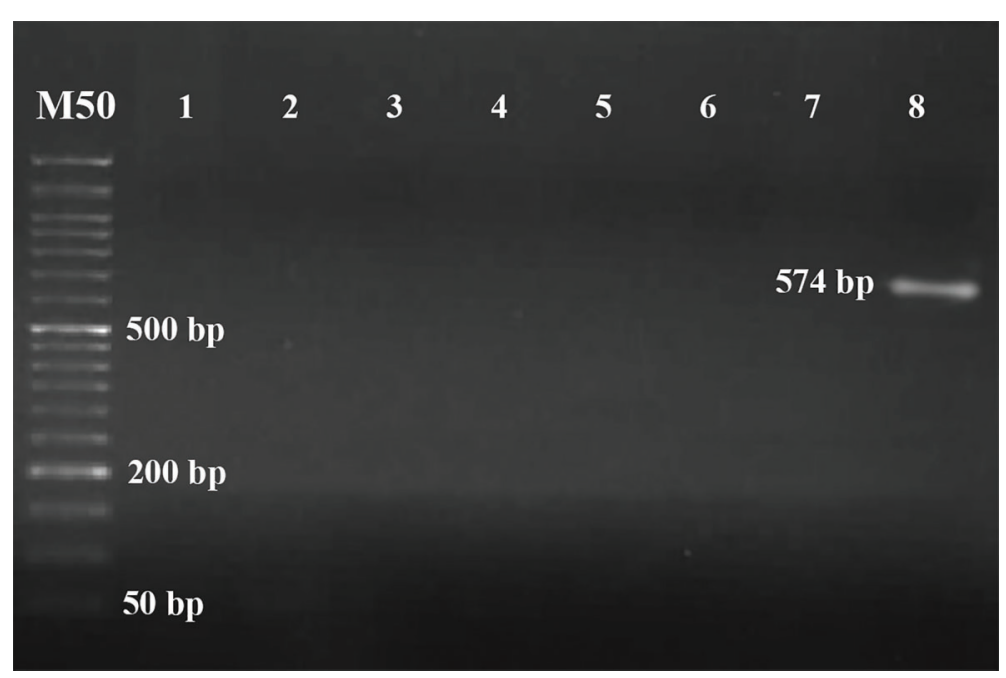

Figure 2. Electrophoresis of studied samples using CIB4 primers in Kermani sheep on $2 \%$ agarose gel. M50: size marker. Lanes 1-8 are brain, heart, lung, spleen, kidney, liver, ovary and testis, respectively. 

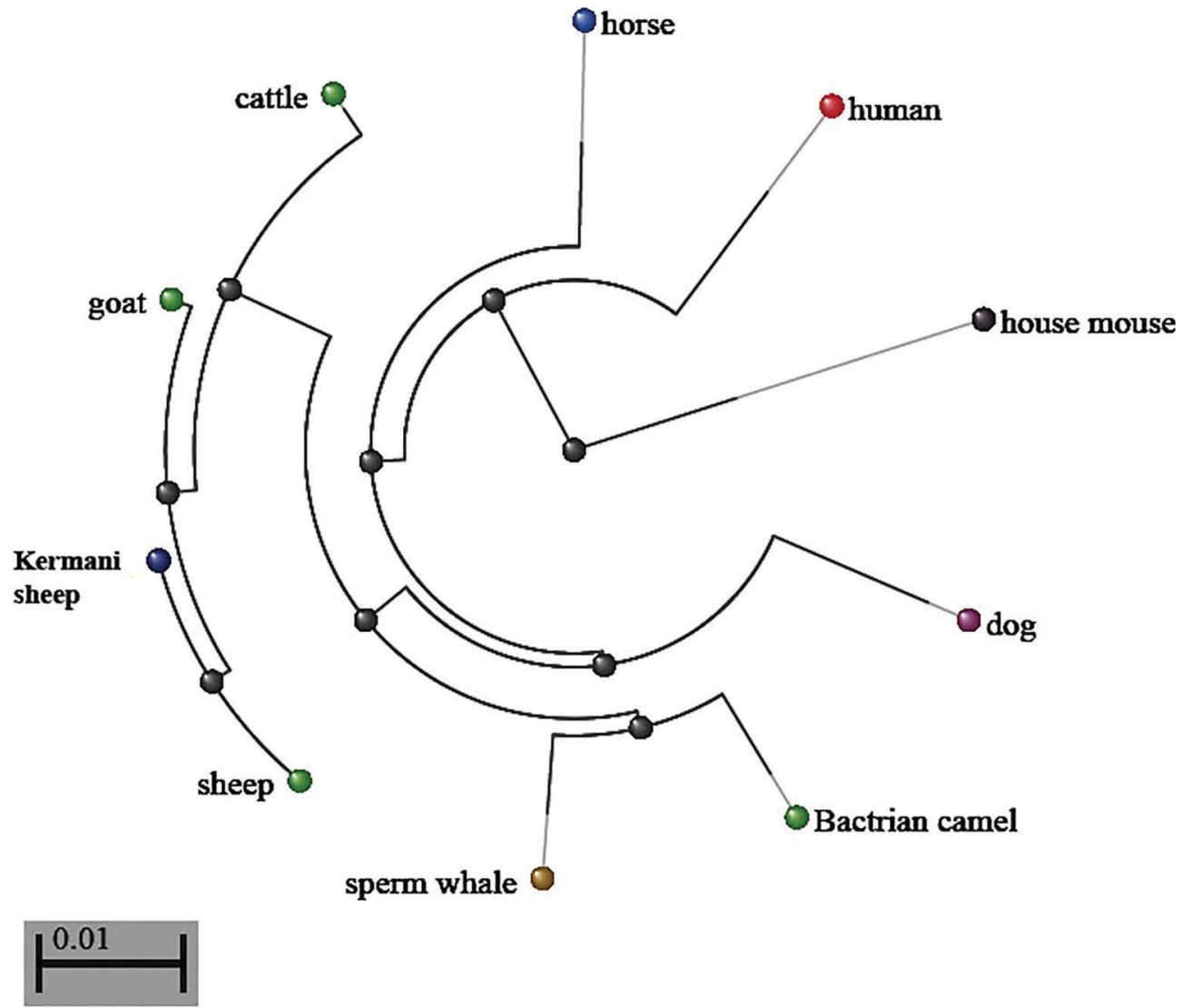

Figure 4. Phylogenetic tree for several CIB4 genes in 9 species. The sheep CIB4 gene nucleotide sequence was aligned with other homologous CIB4 genes. The plylogenetic tree was constructed by neighbor-joining method using MEGA4.1 software. The GenBank accession No. of CIB4 gene are Ovis aries (FJ039532), Capra hircus (NC 022313), Bos Taurus (AC 000178.1), Camelus bactrianus (XM_010972084.1), Physeter catodon (XM_007108419.1), Canis lupus familiaris (XM_003432152.2), Equus caballus (XM_001502860.3), Homo sapiens (NC_000002.12) and Mus musculus (BC118938.1).

Table 1. Amino acid composition of ClB4 gene in Kermani sheep.

\begin{tabular}{|c|c|c|c|c|c|c|c|c|c|c|c|c|c|c|c|c|c|c|c|}
\hline \multicolumn{20}{|c|}{ Amino acid name with 3 letters } \\
\hline Ala & Arg & Asn & Asp & Cys & Gln & Glu & Gly & His & Ile & Leu & Lys & Met & Phe & Pro & Ser & Thr & Trp & Tyr & Val \\
\hline \multicolumn{20}{|c|}{ Amino acid name with 1 letter } \\
\hline A & $\mathrm{R}$ & $\mathrm{N}$ & D & $\mathrm{C}$ & $Q$ & $\mathrm{E}$ & G & $\mathrm{H}$ & I & L & $\mathrm{K}$ & M & $\mathrm{F}$ & $\mathrm{P}$ & S & $\mathrm{T}$ & W & $\mathrm{Y}$ & V \\
\hline \multicolumn{20}{|c|}{ Number } \\
\hline 8 & 9 & 11 & 16 & 6 & 6 & 15 & 5 & 6 & 9 & 22 & 6 & 7 & 15 & 6 & 16 & 6 & 2 & 6 & 8 \\
\hline \multicolumn{20}{|c|}{ Percent } \\
\hline 4.3 & 4.9 & 5.9 & 8.7 & 3.2 & 3.2 & 8.1 & 2.7 & 3.2 & 4.9 & 11.9 & 3.2 & 3.8 & 8.1 & 3.2 & 8.7 & 3.2 & 1.1 & 3.2 & 4.3 \\
\hline
\end{tabular}

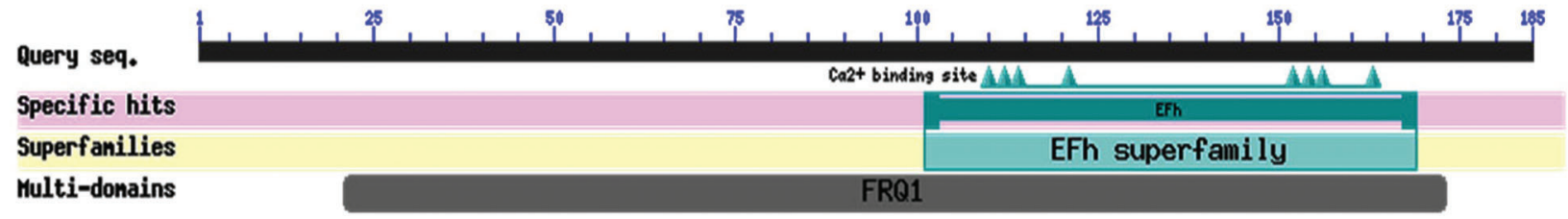

Figure 5. The predicted domain of Kermani sheep CIB4 protein. EFh domains range from amino acid 101 to 171 , including a switch region I starting from the amino acid 101 to the amino acid 129 and a switch region II from amino acid 143 to 171 . 
Target name :

Seq. length :

Sequence :

Secondary structure :

Model length :
Q03096

\section{5}

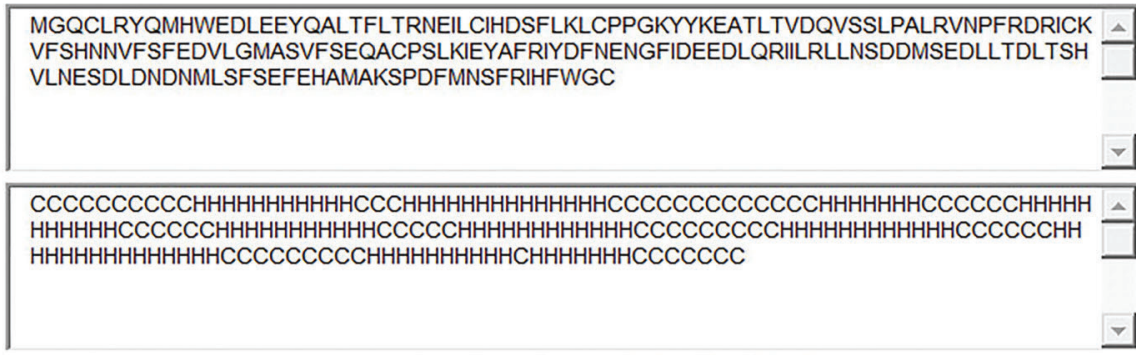

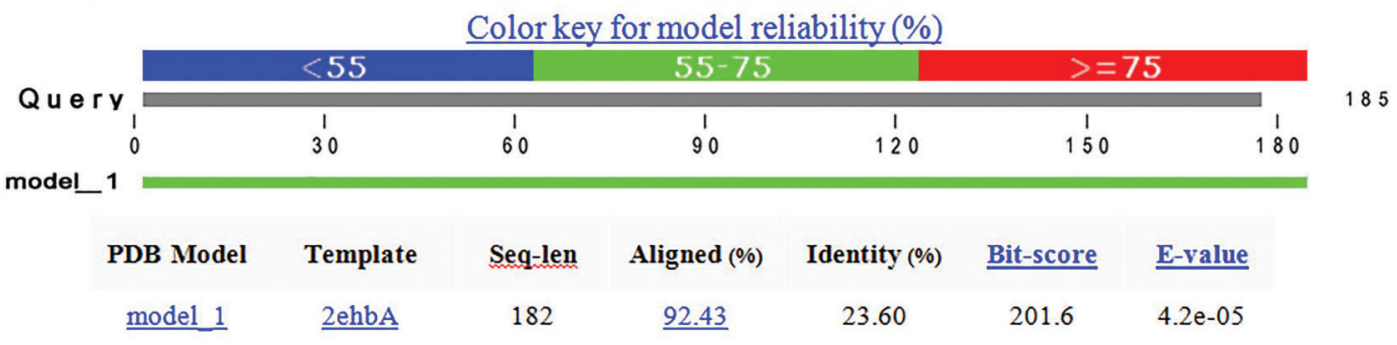

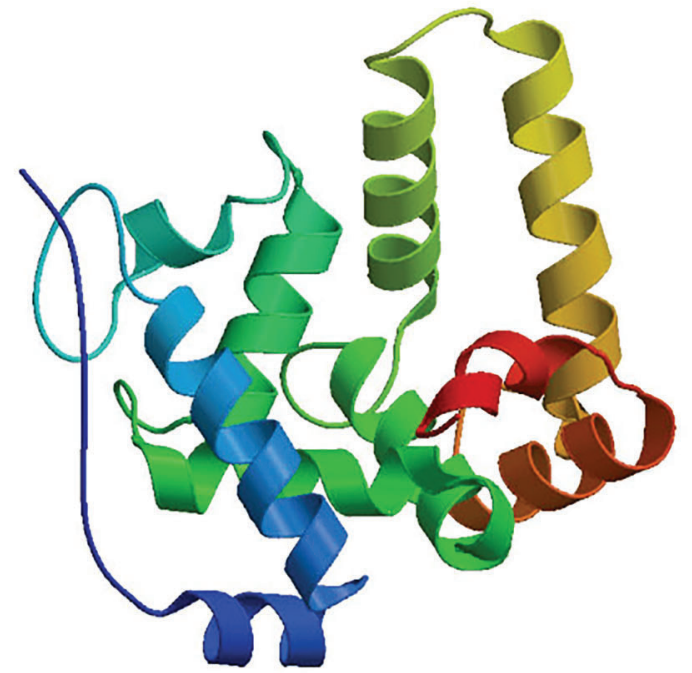

Figure 6. Protein characteristics and three-dimensional structures of CIB4 for Kermani sheep.

the STRING program is given in Figure 7. As shown, CIB4 has an interaction with protein phosphatase 3 catalytic subunit beta isozyme (PPP3CB), serine/threonine-protein phosphatase $2 \mathrm{~B}$ catalytic subunit gamma isoform (PPP3CC) and serine/threonine-protein phosphatase $2 \mathrm{~B}$ catalytic subunit alpha isoform (PPP3CA), that are three different isozymes of human PPP3C (22). Protein phosphatase 3 (PPP3) is also called calcineurin and phosphatase 2B (PP2B) (22). This protein is a serine/threonine protein phosphatase that is tightly regulated by $\mathrm{Ca}^{2+} /$ calmodulin and plays critical roles in many calcium-mediated signal transduction pathways (22). PPP3 is a heterodimer composed of two subunits, a catalytic subunit PPP3C (also called calcineurin A) and a regulatory subunit PPP3R (also called calcineurin B). Myosin-3 (MYH3) and plasma membrane calcium-transporting ATPase (ATP2B), or PMCA, also showed interactions with CIB4 protein.

\section{Discussion}

In the human genome, $C / B 1, C / B 2, C / B 3$ and $C / B 4$ have been determined (23) and only $C / B 1$ has been completely studied $(1,8)$. In animals, there are few studies on these genes. Lately, the $C / B 1$ and $C / B 4$ were characterized $(3,13)$. The sheep CIB4 gene contains eight exons and seven introns, which is similar to the genomic 

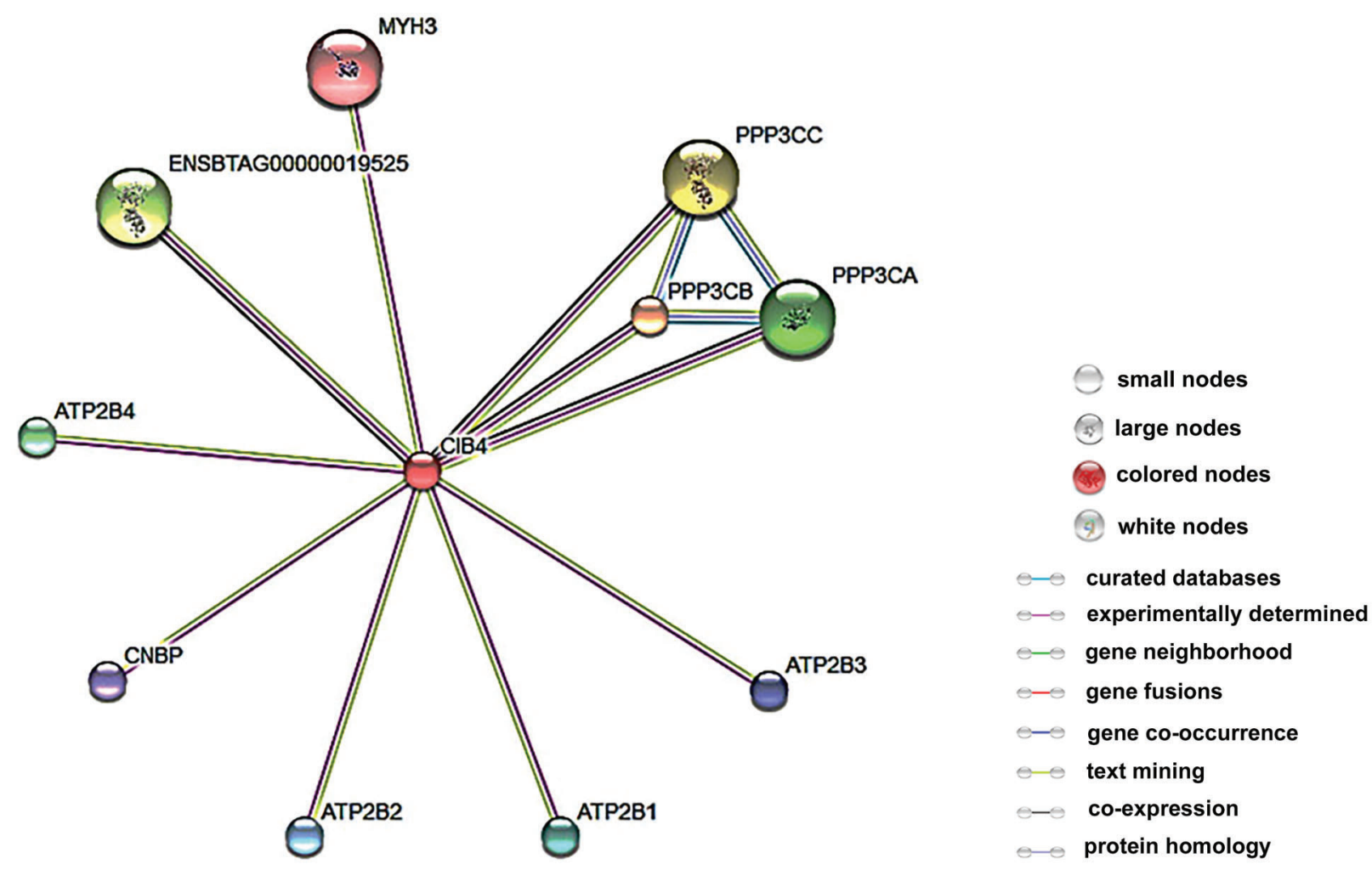

Your Input:

CIB4

calclum and Integrin-blinding family member 4 (185 as)

Predicted Functional Partners:

\begin{tabular}{|c|c|c|c|c|c|}
\hline Ө PPP3C8 & protein phosphatase 3, catalytic subunit, beta lsozyme (139 as) & - & - & - & 0.657 \\
\hline Ө PPP3CC & serine/threonine-proteln phosphatase $2 B$ catalytic subunit gamma isoform (512 aa) & - & - & $\bullet$ & 0.657 \\
\hline$\ominus$ ENSBTAG00000019525 & serine/threonine-proteln phosphatase $2 B$ catalytic subunit beta tsoform (369 aa) & - & - & $\bullet$ & 0.657 \\
\hline - PPP3CA & Serine/threonlne proteln phosphatase 28 catalytte subunft alpha isoform; Calcium-dependent, calmodulinst... & - & - & $\bullet$ & 0.657 \\
\hline$\theta$ ATP2B4 & plasms membrane calalum-transporting ATPase 4 (1028 as) & & - & $\bullet$ & 0.642 \\
\hline - ATP2B1 & plasma membrane calchum-transporting ATPase 1 (1220 as) & & - & $\bullet$ & 0.642 \\
\hline O ATP2B2 & plasma membrane caldum-transporting ATPase 2 (1198 as) & & - & $\bullet$ & 0.642 \\
\hline ATP2B3 & plasma membrane caldum-transporting ATPase 3 (1206 aa) & & $\bullet$ & $\bullet$ & 0.642 \\
\hline O CNBP & Cellular nuclelo acdd-b/nding proteln; Single stranded DNA-binding proteln, with speclficity to the sterol regulato... & & $=$ & $\bullet$ & 0.627 \\
\hline MYH3 & myasin-3 (1940 as) & & - & • & 0.591 \\
\hline
\end{tabular}

Figure 7. Kermani sheep CIB4 interaction with other predicted proteins and description of predicted functional partners using the STRING program. Different line colors represent the types of evidence for the association. Line thickness relates to combined score. Small nodes are protein of unknown 3D structure. Large nodes are some 3D structures known or predicted. Colored nodes are query proteins and first shell of interactors. White nodes are second shell of interactors. Edges are protein-protein associations. Associations are meant to be specific and meaningful, i.e., proteins jointly contribute to a shared function. This does not necessarily mean they are physically binding to each other. Known interactions are from curated databases or are experimentally determined. Predicted interactions are gene neighborhood, gene fusions and gene co-occurrence. Others are text mining, co-expression, and protein homology.

structure of CIB4 gene in other species (3). The CIB family has not been studied in Kermani sheep until now.

Real time PCR results showed that CIB4 gene is expressed only in testis of Kermani sheep, which confirm results of $\mathrm{Yu}$ et al. (3). They demonstrated that the CIB4 gene was expressed in testis of small tail Han sheep,
Texel and Dorset sheep breeds. Hence, this may suggest that the CIB4 gene plays a role in male fertility.

The results of CIB4 amino acid sequence identity suggested that the percentage of identical protein sequences of CIB4 ranged from 96 to $100 \%$. Based on the phylogenetic analysis, the sheep CIB4 has close relationship 
with goat and cattle first, and then with camel and whale, while dog and horse are from a distinct grouping with the human and mouse. Results of $\mathrm{Yu}$ et al. (3) showed that the sheep CIB4 appears to be closely related to that of cattle and horse, while the human and chimpanzee are a separate grouping with the mouse; the rat is from an even more distant grouping. Close relationship between sheep and cattle was found in both investigations. In another study, Yu et al. (13) found that the sheep CIB1 has a close relationship with cattle and pig, whereas horse, mouse and rat formed another separate group. Human, chimpanzee and rhesus monkey formed their own distinct group, while the CIB1 in $X$. laevis, $X$. tropicalis and chicken were more distant from their mammalian counterparts.

Predicted domains with SMART software showed that the deduced sheep CIB4 protein contains two characteristic EF-hand domains, which is similar to the CIB4 in other species. These results were similar to results of Yu et al. (3) reported in small tail Han sheep. Yu et al. (13) reported $2 \mathrm{EF}$-hand domains for CIB1 gene in small tail Han sheep, the first starting at amino acid position 107 and ending at amino acid position 135 and the second was located at position 152-185.

EF-hands are calcium-binding motifs that usually occur at least in pairs. CIB4 protein of Kermani sheep has also a region named FRQ1 that starts at amino acid position 21 and ends at amino acid position 173 (Figure 5).

Circular dichroism spectroscopy studies by Huang et al. (4) on purified CIB2-4 have revealed that CIB2, CIB3, and CIB4 all contain considerable levels of alpha helical secondary structures when they bind $\mathrm{Mg}^{2+}$ or $\mathrm{Ca}^{2+}$. Similarly, the predicted secondary structure of the Kermani sheep CIB4 showed $59.46 \%$ helix $(\mathrm{H})$ and $40.54 \%$ the rest $(C)$. Moreover, observation of Huang et al. (4) on purified CIB2-4 was similar to calmodulin (24). According to the secondary structures, the most separate isoform in the CIB family was $C I B 3$, because in comparison with the other isoforms it contains the largest alpha helix percentage, and the $\mathrm{Mg}^{2+}$-bound form includes more secondary structural elements than the $\mathrm{Ca}^{2+}$-bound form (4).

EF-hand domains have calcium-binding motif including varied superfamily of calcium sensors and calcium signal. A comparison between Kermani sheep CIB4 sequence with other species demonstrated a high degree of conservation, especially in two regions from 101 to 129 (KIEYAFRIYDFNENGFIDEEDLQRIILRL) and from 143 to 171 (LTSHVLNESDLDNDNMLSFSEFEHAMAKS) amino acids, indicating that these two regions might be important functional domains.

$\mathrm{N}$-terminal $\mathrm{N}$-myristoylation is a lipid anchor modification of eukaryotic and viral proteins targeting them to membrane locations, thus changing the cellular function of modified proteins. Protein myristoylation is critical in many pathways; e.g., in signal transduction, apoptosis, or alternative extracellular protein export. Only $\mathrm{N}$-terminal glycines are myristoylated (leading methionines are cleaved prior to myristoylation). CIB1 was shown to carry a myristoyl group (10) at its N-terminus, but it was also found that non-myristoylated $C I B 1$ can interact with allb in vitro $(1,25)$. CIB2 and $C I B 3$, but not $C I B 4$, have been suggested to be myristoylated based on sequence analysis (1). Aligned with these reports, we did not observe any myristoylation site in CIB4 protein of Kermani sheep.

Based on fluorescence experiment results of Huang et al. (4), CIB2 likely interacts with the membrane-proximal domain of the integrin $\alpha 7 \mathrm{~B}$ subunit $(\alpha 7 \mathrm{~B}-\mathrm{M})$ and previous studies also proposed C-terminal end fragment ( $\alpha$ 7B-C). $\alpha$ Ilb interacts selectively with CIB3 and CIB4 under distinct metal-bound conditions, which can suggest that CIB3 and (or) CIB4 modulate activation of the integrin $\alpha \mathrm{llb} \beta 3$ subunits in vivo. These differential responses of $\alpha$ Ilb to apo-, $\mathrm{Mg}^{2+}$-, and $\mathrm{Ca}^{2+}-\mathrm{ClB} 3$ and $\mathrm{CIB} 4$ may also indicate specific relationships between the calcium and integrin signaling pathways. Further work is needed to identify the functional binding partners for these new CIB proteins and determine their high-resolution structures in animals, especially in Kermani sheep.

As seen in Figure 7, based on description and functional different proteins, CIB4 has an interaction with three different isozymes of human PPP3C (26). Previous studies show that PPP3CC is particularly expressed in testis, implying that it may be important for testicular maturation and meiosis (27). Liu et al. (22) proposed that PPP3RL adjust the actuality of PPP3CC in human and may be present in calcium-mediated signal transduction pathways of testis.

Figure 7 also shows the interaction of myosin-3 (MYH3) with CIB4 protein. A number of myosin classes, including myosin I, myosin III and myosin V (28-31) are known to bind calmodulin at the light-chain-binding motifs. Moreover, calcium-mediated adjustment of myosin activity, the binding of calmodulin to myosins could enable its separation into specific cellular compartments. It has been found that myosin VIIA is expressed in the lung, kidney, testis and inner ear $(32,33)$; therefore, it can be said that the CIB4 acts as myosin, but more accurate studies need to be performed.

PMCA is a transport protein in the plasma membrane of cells and acts to eliminate calcium $\left(\mathrm{Ca}^{2+}\right)$ from the cell. It was shown that it is essential for adjusting the amount of $\mathrm{Ca}^{2+}$ in every eukaryotic cell function. The cutting of the PMCA4 gene failed to cause a very evident general pathological phenotype (34), but local defects were present. Because PMCA4 is extensively expressed, it has also been suggested to play a housekeeping role. However, it has now appeared that PMCA4 plays more specialized roles, and is not only necessary for the general function of controlling $\mathrm{Ca}^{2+}$ homeostasis in every cell. One eminent deficiency caused by PMCA4 dysfunction was 
male infertility, showing the influence of the PMCA4 pump in the testis, where it represents more than $90 \%$ of the total PMCA protein (35).

Hence, it can be concluded that CIB4 may be important for testicular maturation and meiosis. However, further studies are needed to identify the role of the CIB4 gene in fecundity and functional binding partners for CIB

\section{References}

1. Yamniuk AP, Vogel HJ. Insights into the structure and function of calcium- and integrin-binding proteins. Calcium Bind Prot 2006; 1: 150-155.

2. DeNofrio JC, Yuan WP, Temple BR, Gentry HR, Parise LV. Characterization of calcium-and integrin-binding protein 1 (CIB 1) knockout platelets: Potential compensation by $C / B$ family members. Thromb Haemost 2008; 100: 847-856.

3. Yu Y, Zhang $Y$, Song $X$, Jin M, Guan Q, Zhang Q, et al. Alternative splicing and tissue expression of CIB4 gene in sheep testis. Anim Reprod Sci 2010; 120: 1-9, doi: 10.1016/ j.anireprosci.2010.01.004.

4. Huang $\mathrm{H}$, Bogstie JN, Vogel HJ. Biophysical and structural studies of the human calcium-and integrin-binding protein family: understanding their functional similarities and differences. Biochem Cell Biol 2012; 90: 646-656, doi: 10.1139/ o2012-021.

5. Naik UP, Patel PM, Parise LV. Identification of a novel calcium-binding protein that interacts with the integrin alpha (Ilb) cytoplasmic domain. J Biol Chem 1997; 272: 46514654, doi: 10.1074/jbc.272.8.4651.

6. Venter JC, Adams MD, Myers EW, Li PW, Mural RJ, Sutton GG. The sequence of the human genome. Science 2001; 291: 1304-1351, doi: 10.1126/science.1058040.

7. Kostyak JC, Naik UP. Calcium-and integrin-binding protein 1 regulates endomitosis and its interaction with Polo-like kinase 3 is enhanced in endomitotic Dami cells. PLOS ONE 2011; 6: e14513, doi: 10.1371/journal.pone.0014513.

8. Yuan W, Leisner TM, McFadden AW, Clark S, Hiller S, Maeda N. CIB1 is essential for mouse spermatogenesis. Mol Cell Biol 2006; 26: 8507-8514.

9. Wu X, Lieber MR. Interaction between DNA-dependent protein kinase and a novel protein, KIP. Mutat Res 1997; 385: 13-20, doi: 10.1016/S0921-8777(97)00035-9.

10. Stabler SM, Ostrowski LL, Janicki SM, Monteiro MJ. A myristoylated calcium-binding protein that preferentially interacts with the Alzheimer's disease presenilin 2 protein. J Cell Biol 1999; 145: 1277-1292, doi: 10.1083/jcb.145. 6.1277.

11. Blazejczyk M, Sobczak A, Debowska K, Wisniewska MB, Kirilenko A, Pikula S. Biochemical characterization and expression analysis of a novel EF-hand $\mathrm{Ca}^{2+}$ binding protein calmyrin2 (Cib2) in brain indicates its function in NMDA receptor mediated $\mathrm{Ca}^{2+}$ signaling. Arch Biochem Biophys 2009; 487: 66-78, doi: 10.1016/j.abb.2009.05.002.

12. Häger M, Bigotti MG, Meszaros R, Carmignac V, Holmberg $\mathrm{J}$, Allamand V, et al. CIB2 binds integrin alpha 7B beta 1D and is reduced in laminin alpha 2 chain-deficient muscular dystrophy. J Biol Chem 2008; 283: 24760-24769, doi: 10.1139/o2012-021. proteins and to determine their high-resolution structures in animals, especially in Kermani sheep.

\section{Acknowledgments}

The authors thank all individuals who willingly participated in the study.

13. Yu Y, Song XM, Du LX, Wang CD. Molecular characterization of the sheep CIB1 gene. Mol Biol Rep 2009; 36: 17991809, doi: 10.1007/s11033-008-9383-4.

14. Zamani $P$, Akhondi M, Mohammadabadi MR. Associations of Inter-Simple Sequence Repeat loci with predicted breeding values of body weight in sheep. Small Ruminant Res 2015; 132: 123-127, doi: 10.1016/j.smallrumres.2015.10.018.

15. Mohammadabadi MR, Sattayimokhtari R. Estimation of (co) variance components of ewe productivity traits in kermani sheep. Slovak J Anim Sci 2013; 46: 45-51.

16. Shojaei M, Abadi MR, Fozi M, Dayani O, Khezri A, Akhondi $M$. Association of growth trait and Leptin gene polymorphism in Kermani sheep. J Cell Mol Res 2010; 2: 67-73.

17. Khodabakhshzadeh R, Mohamadabadi MR, Esmailizadeh AK, Moradi Shahrebabak H, Bordbar F, Ansari Namin S. Identification of point mutations in exon 2 of GDF9 gene in Kermani sheep. Polish J Vet Sci 2016; 19: 281-289, doi: 10.1515/pjvs-2016-0035.

18. Khodabakhshzadeh R, Mohamadabadi MR, Esmailizadeh AK, Moradi Shahrebabak H, Bordbar F, Ansari Namin S. Identify of $G \rightarrow A$ point mutation at positions 477 and 721 in exon 2 of GDF9 gene in Kermani sheep. Modern Genet 2015; 10: 261-268 (in Persian)., doi: 10.22103/jab.2016.1542.

19. Khodabakhshzadeh R, Mohamadabadi MR, Esmailizadeh AK, Moradi Shahrebabak H, Bordbar F, Ansari Namin S. Study of mutations available in first-halfexon 2 of GDF9 gene in crossbred sheep born from crossing of Romanov rams with Kermani ewes. Iranian J Anim Sci Res 2015; 6: 395-403 (in Persian).

20. Pfaffl MW, Horgan GW, Dempfle L. Relative expression software tool $\left(\mathrm{REST}^{\odot}\right)$ for group-wise comparison and statistical analysis of relative expression results in real-time PCR. Nucleic Acids Res 2002; 30: e36, doi: 10.1093/nar/30.9.e36.

21. Tamura K, Dudley J, Nei M, Kumar SM. Evolutionary Genetics Analysis (MEGA) software version $4.0 \mathrm{Mol} \mathrm{Biol}$ Evol 2007; 4: 1596-1599, doi: 10.1093/molbev/msm092.

22. Liu L, Zhang J, Yuan J, Dang Y, Chen X, Xu J, Yu L. Characterization of a human regulatory subunit of protein phosphatase 3 gene (PPP3RL) expressed specifically in testis. Mol Biol Rep 2005; 32: 41-45, doi: 10.1007/s11033004-4250-4.

23. Gentry HR, Singer AU, Betts L, Yang C, Ferrara JD, Sonde JJ. Structural and biochemical characterization of CIB1 delineates a new family of EF-hand-containing proteins. Chem 2005; 280: 8407-8415.

24. Ishida H, Vogel HJ. Protein-peptide interaction studies demonstrate the versatility of calmodulin target protein binding. Protein Pept Lett 2006; 13: 455-465, doi: 10.2174/0929 86606776819600 . 
25. Huang $\mathrm{H}$, Vogel HJ. Structural basis for the activation of platelet integrin allb3 by calcium-and integrin-binding protein 1. J Am Chem Soc 2012; 134: 3864-3872, doi: 10.1021/ ja2111306.

26. Wang $M G$, Yi $H$, Guerini $D$, Klee $C B$, McBride OW, Calcineurin A. Alpha (PPP3CA), calcineurin A beta (PPP3CB) and calcineurin B (PPP3R1) are located on human chromosomes $4,10 \mathrm{q} 21 \rightarrow \mathrm{q} 22$ and $2 \mathrm{p} 16 \rightarrow \mathrm{p} 15$ respectively. Cytogenet Cell Genet 1996; 72: 236-241, doi: 10.1159/ 000134198.

27. Muramatsu T, Kinacaid RL. Molecular cloning and chromosomal mapping of the human gene for the testis-specific catalytic subunit of calmodulin-dependent protein phosphatase (calcineurin A). Biochem Biophys Res Commun 1992; 188: 265-271, doi: 10.1016/0006-291X(92)92379-C.

28. Espreatico EM, Cheney RE, Matteoli M, Nascimento AAC, Camilli PV, Larson RE. De and Primary structure and cellular localization of chicken brain myosin-V (p190), an unconventional myosin with calmodulin light chains. J Cell Biol 1992; 119: 1541-1558, doi: 10.1083/jcb.119.6.1541.

29. Cheney RE, O'Shea MK, Heuser JE, Coelho MV, Wolenski JS, Espreafico EM, et al. Brain myosin-V is a two-headed unconventional myosin with motor activity. Cell 1993; 75 : 13-23, doi: 10.1016/S0092-8674(05)80080-7.
30. Wolenski JS, Hayden SM, Forscher P, Mooseker MSI. Calciumcalmodulin and regulation of brush border myosinand mechanochemistry. J Cell Biol 1993; 122: 613-621, doi: 10.1083/jcb.122.3.613.

31. Cope MJT, Whisstock J, Rayment I, Kendrick JJ. Conservation within the myosin motor domain: implications for structure and function. Structure 1996; 4: 969-987, doi: 10.1016/ S0969-2126(96)00103-7.

32. Gibson F, Walsh J, Mburu P, Varela A, Brown KA, Antonio M. A type VII myosin encoded by the mouse deafness gene shaker-I. Nature 1995; 374: 62-64, doi: 10.1038/374062a0.

33. Self T, Mahony M, Fleming J, Walsh J, Brown SD, Steel KP. Shaker-1 mutations reveal roles for myosin VIIA in both development and function of cochlear hair cells. Development 1998; 125: 557-566.

34. Schuh K, Cartwright EJ, Jankevics E, Bundschu K, Liebermann J, Williams JC. Plasma membrane Ca2p ATPase 4 is required for sperm motility and male fertility. Chem 2004; 279: 28220-28226, doi: 10.1074/jbc.M3125 99200.

35. Prasad V, Okunade GW, Miller ML, Shull GE. Phenotypes of SERCA and PMCA knockout mice. Biochem Biophys Res Commun 2004; 322: 1192-1203, doi: 10.1016/j.bbrc. 2004.07.156. 